\title{
Study on Inefficient Factors and Storage Reliability for the Antiaircraft Missile
}

\author{
LI Ke, LI Yan, JIANG Huixia, ZHANG Kai \\ 4th Department, Shijiazhuang Mechanical Engineering College, SHIJJIAZHUANG, HEBEI, CHINA, \\ 050003 \\ Ken_like@126.com
}

Keywords: antiaircraft missile; inefficient factors of storage; storage reliability

\begin{abstract}
In the paper, the antiaircraft missile is assumed as the researched object, and its inefficient factors and storage reliability is focused to be analyzed. The weaknesses of storage of the antiaircraft missile could be confirmed with its inefficient factors analysis of storage, reliability analysis of storage and reliability assessment of storage. So it is may be easy for operational personnel to take effective measures to improve conditions of storage and usage of the antiaircraft missile and extend its life; The results of the paper may not only be data support for making codes of the rational use of the antiaircraft missile, maintenance measures and etc. but also be guidance for life-extension repairing work of the antiaircraft missile, effective usage of resources, reducing the use of maintenance costs.
\end{abstract}

\section{Analysis of Inefficient Factors of Storage of the Antiaircraft Missile}

Storage reliability is usually defined as "the ability of equipment under the specified storage conditions to maintain a required function within a specified storage time." The trait of usage for an antiaircraft missile (it will briefly be called the missile in under lines.) is long-term storage and one-shot firing. In order to ensure the missile always to be in good condition within long-term storage, the missile is needed periodic inspection and test, repairing on time if there are problems. Transport, mounding, duty, power-on training and other tasks are possible during life cycle of the missile. Therefore, factors affecting reliability and longevity of the missile storage include natural factors and human factors. Natural factors mainly refer to the missile storage environment temperature, humidity conditions; human factors mainly refer to missile transport, mechanical vibration or shock of mounding, power-on training and electrical shock during testing process. After a period of storage, transport, mounding, power-on testing, fault repairing and other operations, electrical components inside the missile would be occurred parameters over proof, and mechanical parts inside the missile would be occurred wear, corrosion, and plastic rubber elements would appear brittle, aging etc. These phenomena caused by natural and human factors would generate degrading of reliability the missile storage or shortening the life of the missile ${ }^{[1]}$. The missile is constructed by various subsystems or modules, long-term storage has different effects on missile accessories ${ }^{[2]}$, Storage has little affect for reliability of some accessories, for example, pieces of metal structures; others components, such as seals, charge and missile batteries, there would be performance changes, or even failure; some electrical components required high parameters would generate parameter shift, even be over range of technical requirements or cause fault for long-term storage. By means of statistical data of maintenance and life-extension maintenance test of one antiaircraft missile, which is exceeded its design service time, main performance changes of the missile under long-term storage conditions include:(1) The metal parts wear, rust, and corrode. Corrosion or rust of cabin, rudders, wings or other alloys, and other metal parts mainly affect their normal performance; contact oxidation due to corrosion would induce poor conductivity. (2) Aging deterioration of the non-metallic parts. Various degrees of deterioration of aging and dry exist in different rubbers, sponge mats, seals, greases and, affecting the seal elastomers and components, resulting in leaks, oil spills, and some mechanics does not work properly due to poor lubrication. (3) Parameters are over proof. With growth of storage or usage 
time, onboard instruments of missile and electrical equipment would gradually generate parameters drift, sensitivity decreased, poor symmetry of parameters, waveform distortion and so on. (4) Degradation of pyrotechnic performance. Deformation, cracking, out sticking and other phenomena caused by long-term storage of engine charge and its cladding layer, insulating layer, liner, would make performance of engine charge, electric squib, start blasting detonators and explosive bolts to decline. (5) Human injuries during operation or maintenance due to improper usage. Human injuries includes pressure, touch, scratch in loading and unloading process, and other damage, for example, components damage, socket and pin damage, are caused by non-standard operations while performing detection and maintenance.

\section{Analysis on reliability of missile storage}

By means of statistical data of maintenance, life-extension maintenance test and shooting practice of one antiaircraft missile which is exceeded its design service time, the reliability of missile storage could be analyzed. Long-term storage has different impact on modules, maintainability of various components are not exactly same. So missile modules could be divided into four categories to be studied ${ }^{[3]}$ : The first category has extremely high reliability, long-term storage has little impact to them, or their storage life are much longer than other missile modules; second category is available for regular testing, and they could be repaired when fault are detected, or they could be replaced with spare components; the third category isn't available for regular testing, but their change trend of performance parameters could be forecasted; The fourth category is relatively short shelf-life or easily be regularly replaced in order to meet the required reliability of missile storage. Through analysis on reliability of components storage of missile, the components which are easily damaged can be found.

Storage Reliability of the First Class Modules. The first class modules include airframe structure, shipping launchers, missile cable network, warhead, detonator, explosive bolts. According to the resume of a missile and maintenance records, the modules almost haven't inefficient phenomena. In the case of warhead, all of warheads not only have internal metal parts, but also non-metallic parts, and have chemical composition requirements as well as structural parameters. There are two ways to determine life of a warhead, one is assessment on whether performances of a warhead has significantly worse; the other is to consider security of a warhead service process. The conclusion for sub-sample of detection and test of long-term storage of one warhead is shown as table 1. Combined results from detection and test based on study samples and extended sample of subject of a warhead, the conclusion could be affirmed: after warhead is loaded and to be stored by the form of barrel bomb under specified storage conditions, it could keep its operational performance without maintenance during its expected life.

Storage Reliability of the Second Class Modules. The second modules include remote control answering machine, autopilot, fuse electronics, converter etc. Such components are key components to achieve missile capabilities. They usually have a complex structure, circuits with high sensitivity and high failure rate, and generally need to be tested for its main performance parameters in periodic maintenance. Let's see fuse. Fuse is a sort of photoelectric product, constituted by the optical system, one sensor, electrical circuit etc. Similarly, storage reliability of fuse could be broken down into storage reliability of three previous parts. The conclusion for sub-sample of detection and test of long-term storage of a fuse is shown as table 2.

Regular tests are conducted for electrical parts of fuse; the faulty component in tests is electrical circuit. Therefore the discussion on storage reliability of fuse as a second class member is focused on its electrical portfolio. According to the conclusions, optical parts could be found to have high reliability, whose sub-sample function after long-term storage has not significantly decreased, and therefore could be treated as a first class component; and one sensor due to unavoidable liquid leak problems, and the leak rate is almost substantial linear, so the liquid leak rate would determine the storage life of the sensor, thus affecting the overall life of the fuse and missile.

Storage Reliability of the Third Class Modules. The third class modules include engines and charge, detector of fuse. The components couldn't regularly be tested, but relevant studies have 
shown that the performance parameters of the components have changing tendency; they would be unable to complete their designed function when their parameters change gets one certain extent.

Table 1 study samples of one warhead and conclusions

\begin{tabular}{|c|c|c|l|}
\hline $\begin{array}{c}\text { test project } \\
\begin{array}{c}\text { Visual } \\
\text { inspection }\end{array}\end{array}$ & $\begin{array}{c}\text { Sample } \\
\text { number }\end{array}$ & $\begin{array}{c}\text { Inefficient } \\
\text { number }\end{array}$ & \multicolumn{1}{c|}{ test conclusion } \\
\hline $\begin{array}{c}\text { Non-destructive } \\
\text { test }\end{array}$ & 6 & 0 & $\begin{array}{l}\text { External painting is intact, exposed metal has no rust; various } \\
\text { identities are intact and have no damage phenomena. }\end{array}$ \\
\hline $\begin{array}{c}\text { Performance } \\
\text { Check }\end{array}$ & 6 & $\begin{array}{l}\text { Detonators are in normal positions and not found to be deformed } \\
\text { Waveform controller is normal and has no displacement and } \\
\text { geometric changes } \\
\text { Main charge is full, its cross-section has not any defects and in good } \\
\text { quality } \\
\text { Main charge is filled in silicone rubber groove }\end{array}$ \\
\hline Static burst test & 0 & $\begin{array}{l}\text { The modules of main charge, including front surface, composite } \\
\text { partitions, the front end of a silicone rubber spacer and expansion } \\
\text { booster etc., don't change significantly and the seal is intact } \\
\text { Observed from cross-section, detonators and the center tube are in } \\
\text { the center, no offset } \\
\text { Structural parameters including warhead total length, mass and } \\
\text { center of gravity etc., front or end OD and ID, depth etc. meet } \\
\text { technical requirements; charge is in good explosive performance } \\
\text { Silicone rubber pad, cushion, fragment control parts and other } \\
\text { non-metallic parts, are not found no variation through visual } \\
\text { inspection and in good tensile }\end{array}$ \\
\hline \multirow{2}{*}{6} & 0 & $\begin{array}{l}\text { Static burst test on ground for samples and extended sample of } \\
\text { subject of a warhead are performed. All of test, including two } \\
\text { high-temperature tests , two low temperature tests, two room } \\
\text { temperature tests are in compliance with the performance } \\
\text { requirements }\end{array}$ \\
\hline
\end{tabular}

Table 2 study samples of fuse and conclusions

\begin{tabular}{|c|c|c|c|}
\hline test project & $\begin{array}{l}\text { Sample } \\
\text { number }\end{array}$ & $\begin{array}{l}\text { number of } \\
\text { failures }\end{array}$ & test conclusion \\
\hline $\begin{array}{l}\text { Visual } \\
\text { inspection }\end{array}$ & 5 & (2) & $\begin{array}{c}\text { There are no scratches, bumps, coat paint shedding on the whole } \\
\text { surface of fuse and identities are intact } \\
\text { There are not rust or scratches on optical system glass windows, } \\
\text { mirrors } \\
\text { Connectors are installed correctly, pins and sockets are normal and } \\
\text { don't have needle shrinking, potting is intact too } \\
\text { Rubber pieces have aging; there haven’t surpluses and other } \\
\text { abnormalities }\end{array}$ \\
\hline $\begin{array}{c}\text { Static } \\
\text { electricity }\end{array}$ & 5 & 0 & $\begin{array}{c}\text { The test results of powerless conducting test are accordance with } \\
\text { technical requirements }\end{array}$ \\
\hline $\begin{array}{l}\text { Electrical } \\
\text { Properties }\end{array}$ & 5 & 0 & $\begin{array}{l}\text { The test results of electrical performances testing, which are } \\
\text { included noise voltage level test, the threshold level test, delay time } \\
\text { test, discharge time of detonating capacitor test, are accordance with } \\
\text { technical requirements. The parameters have not significant change } \\
\text { compared with nominal data. }\end{array}$ \\
\hline $\begin{array}{l}\text { Optical } \\
\text { Parametric }\end{array}$ & 5 & 0 & $\begin{array}{l}\text { The test results of optical parameters, which are included angle of } \\
\text { observation field of fuse, angle between the optical axis and the axis } \\
\text { missile body test results, are accordance with technical } \\
\text { requirements. The parameters have not significant change compared } \\
\text { with nominal data. }\end{array}$ \\
\hline detector & 5 & 4 & $\begin{array}{l}\text { The performance testing of leading edge and holding time of } \\
\text { detector is not accordance with technical requirements }\end{array}$ \\
\hline
\end{tabular}

Take an engine for example; it is a little different with other parts of a missile. It is complex, contains many kinds of materials. It is generally difficult to determine whether an engine is at the end of its life except to take the ignition test. As an one-use product, the life of an engine depends on such factors as the performance reduction of the mechanical properties of the charge, sealing performance of sealing devices and adhesive quality among engine interior interfaces (for example, shell, insulation, liner, charge) and so on. By means of a series of tests, which include a long-term storage sub-sample engine integrated performance test and ground firing test, the ignition circuit performance test, combustion chamber and nozzle seat quality test, propellant visual inspection, $\mathrm{X}$-ray detection, physical and chemical performance test, show that energy characteristics, physical and chemical properties of cladding layer, filter performance are in accordance with technical requirements; but with the growth of storage time, the combustion characteristics of the propellant decreased. There is usually not exact function between engine performance parameters and storage time, but a regression equation of performance parameters of an engine and its storage time could 
be established through the regression analysis of mathematical statistics, and storage life of an engine could be evaluated by setting a confidence value.

Storage Reliability of the Fourth Class Modules. The fourth class modules include rubber gaskets and seals, cups, insulation pads, grease, resin elastomer potting material, the launch tube rubber seals and so on, which are in various modules of missile body. Through a long-term storage sub-sample inspection test, the inefficient faults of rubber components mainly include over proof of humility caused by air leakage for seal ring aging of launching cylinder, inefficient gyro caused by oil amount deceased in gyros cavities for silicone oil leakage while gyro seal ring aging, other components polluted caused by silicone oil leakage, and impact to components performance by cushion aging. Resin potting material shows signs of aging after long-term storage, even more several sub-samples of plug crack for inefficient resin potting material with longer storage time; Lubricants decomposition failure occurs during storage, for example, there nearly hasn't grease in bearing of sub-samples after long-term storage. Since the study about such materials is relatively mature and universal, the conclusions and results of the studying domain could be appointed to analyze the similar problems of relevant components ${ }^{[4,5]}$, and life of storage under specified storage conditions about rubber sealing materials, grease, potting material could be obtained.

\section{Assessment on Missile Storage Reliability}

Typically the basic idea about assessment on reliability of product storage is ${ }^{[6]}$ : point estimation and confidence floor of inherent reliability of a product should be obtained according to its store and test data; the conditioned storage reliability could be obtained by point estimation and confidence floor of reliability of a product are calculated at each point of the years known; distribution function of the conditioned storage reliability is assumed to estimate the distribution parameters using profile matching method; the storage reliability of a product at each time of storage is assessed and life of storage of a product could be predicted too.

Assessment on Unit Storage Reliability. The system of a missile is composed of different units. The function structure of storage reliability of the aircraft missile is shown as Figure 1 . That is to say the system of a missile could be seen as a series constituted of several functional units. During an evaluating process of Storage Reliability, assessment of unit-level reliability can not only get independent results used for cell-level analysis, but also it is the basis for evaluation of system-level reliability. At present, there are a lot of assessed models of unit-level reliability; according to types of distributing functions of reliability, the life model could be divided into two, index, normal type, lognormal model, Weibull model, and so on. Each type of distributing functions of reliability is associated with one estimating algorithm for storage reliability and life time.

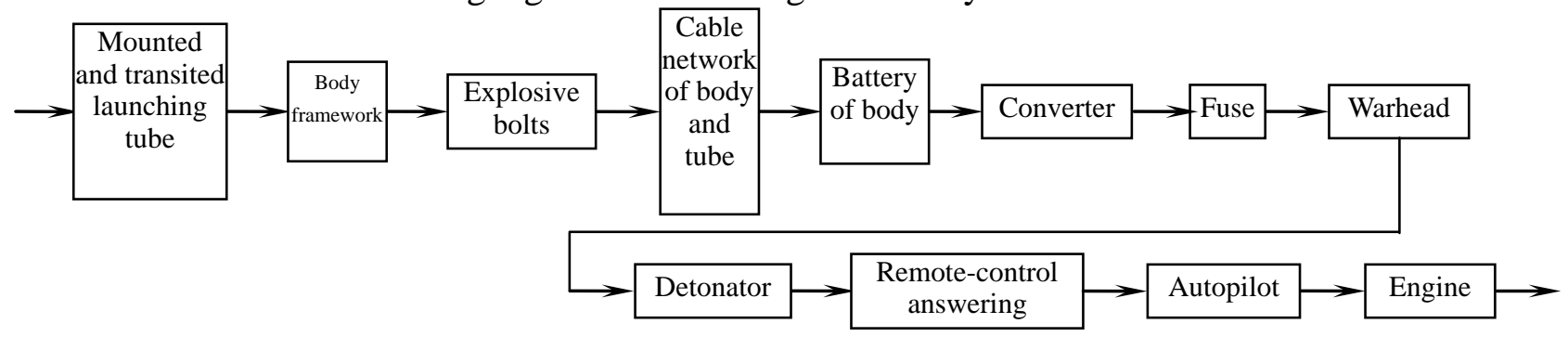

Fig.1 function structure of reliability of storage of the aircraft Missile

Taking electronic circuits in an autopilot, remote-control answering or a fuse as examples, the lives of electronic products are usually accordance with the index variation in terms of relevant analysis. According to statistical data of maintenance test trials, the point estimations of the failure rate $(\hat{\lambda})$, reliability $(\hat{R})$ and low limit of confidence of reliability $\left(R_{L}\right)$ could be calculated to get a predicted distribution curve of the reliability estimation with the storage time, then an index life model of reliability, which is combined with the initial reliability $\left(R_{0}\right)$ of a component, could be set as follow by curve fitting:

$$
R(t)=R_{0} e^{-\lambda t}
$$


Assessment on System Storage Reliability. Reliability of system is the same as reliability of unit and is evaluated by test data. But it is unrealistic to take many times or long time of trials for a large system. Missile is a complex system, its reliability test of storage has a long cycle and high cost, therefore there has only a little reliability test data. When reliability of system-level evaluated, there are insufficient information, small low limit of confidence of reliability and small confidence level, the inherent reliability level of a system couldn't be reflected. Therefore, assessment on reliability of a system could be implemented by combination of reliability model of key components and long-term storage test data of a system, also known as "pyramid" method ${ }^{[7]}$. A schematic diagram of "Pyramid" principle is shown as in Figure 2. "Pyramid" assessment on reliability recognizes that: the assessing information of one upper level could be got from some foundational levels of a system (component-level) by usage of reliability assessing model, that is to say reliability assessing information of one system-level could be got by combination of reliability assessing equivalent information and test information of components at the same system-level. The mentioned process of amounting and synthesizing reliability information is begun from bottom to top according to the hierarchy of a system, and then system-level reliability assessing information to assess reliability of a system could be obtained.

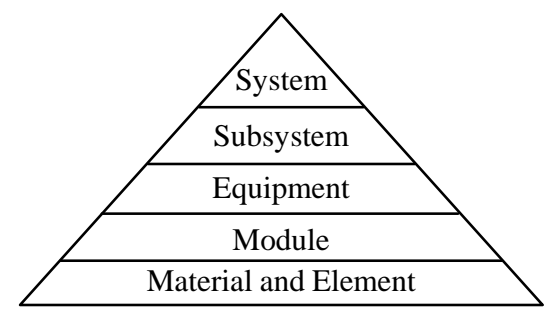

Fig.2 function structure of "Pyramid" assessment on reliability Assessment

In fact, it is the approximate method that is widely adopted, when a complex system is overall assessed by use of the "pyramid" method, let's take the classic L-M method to assess reliability of a series system for example to explain that. Premise that a series system is consisted of $k$ separate units, reliability of one unit is $R_{i}(i=1,2, \cdots, k)$, so reliability of the system $\left(R_{S}\right)$ could be established as follow:

$$
R_{S}=\prod_{i=1}^{k} R_{i}
$$

Assumed the point estimation of reliability of one unit is $\hat{R}_{i}$, the point estimations of reliability of the system is:

$$
\hat{R}_{S}=\prod_{i=1}^{k} \hat{R}_{i}
$$

However, the one-side low limit of confidence of reliability of the system couldn't be directly obtained from the one-side low limit of confidence of reliability of one unit; it should be obtained by reliability integrated approach. With the above evaluation method, comprehensive reliability of one aircraft missile is assessed. There are twelve modules of the missile, the long-life modules, such as framework, warhead, explosive bolts, shipping launchers etc., are not tested during storage, and their reliability hardly change before their electronic components have failures, so reliability of the modules evaluated could be set as 1 . According to the real statistics data of the modules, there is one fault because of air leak of launching barrel. To those modules whose performance parameters have changing tendency, for example, engine, detectors of fuses, it is not convenient to be direct quantitatively evaluated, just to be considered that they are out of their designed lives if only one of their performance parameters does not meet the requirement. Statistics on autopilot, remote answering machines, electronic circuits and combination fuse section components can be measured in accordance with the appropriate information conversion formulas. The point estimation of reliability of a system, which is represented as $\hat{R}$, is calculated, and then the one-side low limit of confidence of reliability of the system, which is represented as $R_{L}$, could be obtained according to a given confidence level $\gamma=1-\alpha$ or obtained by looking up a relevant table. The points, which are 
samples of function $\left(t_{i}, \hat{R}\left(t_{i}\right)\right)$, could be depicted in a coordinates to get a reliability curve. According to analysis based on the curve, storage reliability of a missile is high within a certain time span; over that span, the declining rate of storage reliability becomes accelerated; from a particular time limit, the declining rate of storage reliability becomes steep. So by means of data within a certain period, the index model for storage reliability of a missile could be established in term of matching curve fitting method, and the overall storage life of a missile could be estimated with the model.

\section{Conclusions}

In the paper, storage reliability for the antiaircraft missile is analyzed, which is combination with their maintenance, repairing and repairing tests. By factors of storage failure analyzed, reasons of storage failure could be found; effective methods to improve the conditions of storage and usage could be found, and the life of a missile could be extended too. By analysis and assessment of Storage Reliability, not only be weaknesses of storage of a missile could located, but also reliable data support could be used for acquisition, training, maintenance, security, etc., and be used for repairing and life extension of a missile, more efficient use of resources, reducing maintenance costs.

\section{References}

[1] Sun Liang, Seo Jeong school. Reliability Prediction Model [J] periodic testing of missiles based storage, tactical missile technology, 2004 (4): 16-19.

[2] Liu Chun and Lu Zu Jian. Missile storage reliability evaluation [J], Mathematics in Practice and Theory, July 2001 Volume 31, No. 4: 417-420.

[4] Miao Rong Li, Zhu Feng, Dong Ao account. Cover seals and seal housing assembly before a model life research [J], aviation weapons, 2002 (3): 21-24.

[5] Zhang Kai, Fu Qiang, Huang Yu-hung. Prediction lubricant storage life of [J], mechanical engineering materials, 2005 (10): 43-46.

[6] Pan Jian. Reliability Availability Maintainability Assessment Manual [M]. Beijing: National Defense Industry Press, 1995.

[7] Haifeng. System reliability engineering [M]. Beijing: National Defense Industry Press, 2004: 285-287.

[8] Yangwan Jun. Weapon System Reliability Assessment Algorithm analysis and software design

[D], National University of Defense Technology master's degree thesis, 2002: 5-6. 